\title{
NEW MATERIAL USING CEMENT-BASED MATRIX WITH SELF-REPAIR PROPERTIES BASED ON REACTIVE GRAINS WITH PROTECTIVE COATING
}

\author{
MIRON ZAPCIU ${ }^{a, *}$, CONSTANTIN VOINIȚCHI ${ }^{b}$, NICOLETA IONESCU $^{c}$, \\ MARIUS OLTEANUd
}

\begin{abstract}
This research relates to cement-based matrix materials with self-repairing properties, based on reactive grains (Portland clinker) having the dimensions $90 \ldots 160 \mu \mathrm{m}$ and using a protective coating layer with a thickness of 4-7 $\mu \mathrm{m}$. The material involves the use in mortars or concretes of a smart additive of a clinker reactive material covered with an impermeable polymeric coating that breaks when a crack appears in the material and allows the reaction between water and cement stone components and, consequently, the formation of a crack plugging product consisting in calcium silicate hydrates gels $(\mathrm{CSH})$, superior to that of calcium carbonate precipitation. The intelligent addition is obtained by mixing the reactive material with the solution of a polymer, or with its melt (C8H8)n. The efficiency of coverage exceeds $80 \%$ in most of cases, some of them approaching even $90 \%$. No significant effect of the ratio reactive material/polymer seems to be observed. The degree of healing of the crack is defined in the paper. The method of highlighting the self-repairing effect is based on the amount of electricity passed through the sample. The new material has practically unchanged mechanical properties, a higher hydration capacity and a longer service life-cycle.
\end{abstract}

Keywords: reactive grains, protective coating, self-repairing, new material

a Politehnica University of Bucharest, INCERTRANS SA, Academy of Romanian Scientists, Spl. Independentei 313, sector 6, ZipCode 060042, Bucharest, Romania

b Technical University of Civil Engineering, Blvd Lacul Tei 124, ZipCode 020396 Bucharest

c INCERTRANS SA, Transport Research Institute, Calea Grivitei 391-393, ZipCode 010719, Bucharest, Romania

d SW Umwelttechnik Romania, Str. Zavoiului, Nr. 1, com. Vanatorii Mici, jud. Giurgiu ZipCode 087253, Romania

Corresponding author: miron.zapciu@upb.ro 


\section{INTRODUCTION}

\section{State of the art}

There are currently several attempts to make self-repairing concrete using different principles. Vascular recipes can be used inside the concrete, containing embedded resins or from an external source, additions of superabsorbent polymers, or even the use of bacteria encapsulated together with the necessary nutrients and which, when the crack appears, resume their metabolism, releasing $\mathrm{CO}_{2}$, which carbonates the portlandite resulting from the hydration of the Portland cement and resulting in the clogging of the crack. There are also methods that involve the use of active hydraulic additives that, in the presence of portlandite, will develop hydro-compounds that can ensure the clogging of the crack, or fibers that reduce the width of the crack and allow natural concrete self-repair. The disadvantages are represented by the difficulty of implementing the adopted solutions which have been tested only in laboratory conditions and which do not fit for the implementation on real-site conditions.

There are attempts on the use of polymer-modified self-repairing bitumen (PmB), to increase the elasticity of road layers, to reduce wear and material fatigue at high temperatures. Polymer-based additives are generally used for modified bitumen. Of these additives, styrene-butadiene-styrene copolymers (SBS) are the most commonly used (WIPO patent with identification number WO 2017/116354 A1) [1].

Another example of autogenous healing, but of a cement composite, is made according to patent number 20080261027 from the USA [2], the claims being from The Regents of the University of Michigan. The patent relates to a self-healing cement composite and, in particular, to a fiber-reinforced cement-based composite, which has a self-controlled crack width dimensions from $50 \mu \mathrm{m}$ to a maximum of $150 \mu \mathrm{m}$. Self-healing can occur within a variety of environmental conditions including that in which the material is damaged, as per example by tensile loading. Self-healing in this case was autogenic and observed by the test for analyzing the resistance of concrete to chloride ion penetration, according to the AASHTO T259-80 standard. The composite comprises hydraulic cement, water, sand, fly ash (pozzolanic additive) [19], water reducing agent and short and discontinuous fibers [3-5, 7-9]. The fibers are based on polyvinyl alcohol having diameters between 30 and $60 \mu \mathrm{m}$ and are found in a percentage of $1.5 \%-3.0 \%$ on the related composite volume. The use of superabsorbent polymer was reported too [6].

\section{Polymeric coated reactive grains - Concept Presentation}

The continued hydration of cement grains is considered an essential mechanism of chemical nature, responsible for generating the calcium silicate hydrates gels $(\mathrm{CSH})$, superior to that of calcium carbonate precipitation: 
they are not able just to seal the crack, however, by the means of a high bond strength to the crack walls, they may generate the mechanical recovery of the material, as well [10-13].

Another aspect relates to the currently cement production, based on fine clinker grains contents, with fast initial reactivity in order to reach the fullstrength potential at the age of 28 days [14-17]. After the peak is reached, the hydration process experiences a sudden drop in the continuous hydration process, since the reactive basin is consumed.

The new concept of the authors about self-repairing is to increase the hydration capacity of the concrete using reactive grains addition, polymeric coated for reactivity conservation until the point when it becomes necessary: crack occurrence and consequently the necessity to seal/heal it, when humidity conditions are also ensured (Figure 1).

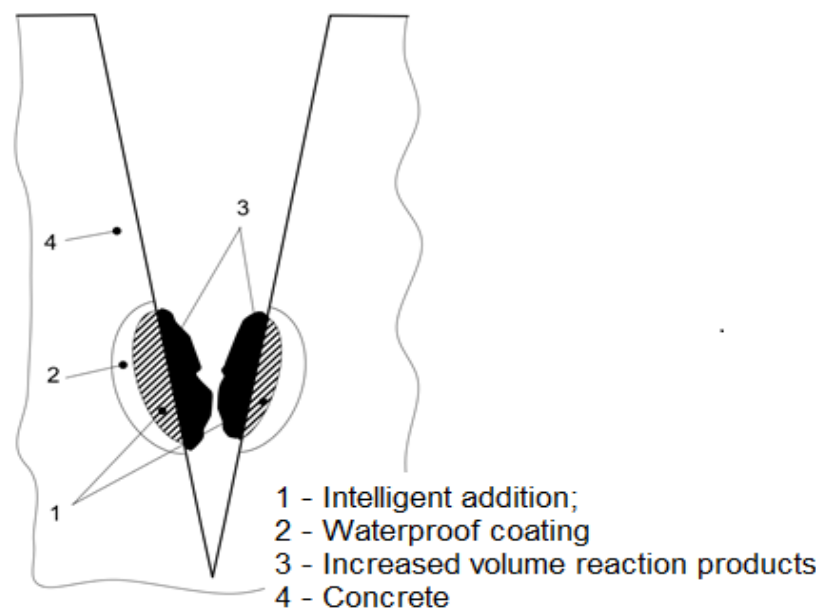

Figure 1. Representation of the concept for the reactive grains

Using polymeric coated reactive grains, the impermeable coating of a clinker material breaks when a crack appears in the material, allowing the reaction between water and cement stone components and, consequently, self-repairing due to the formation of a crack plugging product by generating the calcium silicate hydrates gels [12].

This addition of reactive grains has the following important advantages: -increasing the service life for concrete used in reinforced concrete works in contact with aggressive agents; 
-increasing the uptime between two repairs for reinforced concrete used in infrastructure works;

- the use of recyclable materials in making the smart addition;

- it is extremely practical, being adapted to site conditions.

The research was oriented so as to validate the followings:

- the materials which could be considered proper as reactive grain and protective polymeric cover;

- the encapsulation techniques from waterproofing capacity;

- the potential of self-repairing effect when crack is induced [18].

A smart addition material has been created (reactive grains + protective polymeric cover) capable of generating a self-repairing action after a long period of hydration in the mortar/concrete in wherein is added. The addition consists of an active hydraulic material wrapped in a waterproof polymer film, which breaks when the concrete crack crosses through the particle.

\section{RESULTS AND DISCUSSION}

\section{Reactive grains covering degree}

An active hydraulic material (Portland clinker) with the size of granules between 90 and $160 \mu \mathrm{m}$ wrapped in a polymer film of a thickness of 4-7 $\mu \mathrm{m}$ has been used. Two metods were used: Method 1 using polymer solution in an appropriate solvent and Method 2 using melted polymer, $(\mathrm{C} 8 \mathrm{H} 8) \mathrm{n}$. After the achievement, the granules were passed through the $0,5 \mathrm{~mm}$ sieve for breaking the adhesions between the shells of the granules (Figure 2).

Covering Degree (CD, \%) was determined by using conductivity test on suspensions of covered and uncovered clinker and the Equation (1):

$$
\mathrm{CD}(\%)=100 \times \frac{\text { Cond }_{\mathrm{hp}}-\text { Cond }_{\mathrm{h}}}{\text { Cond }_{\mathrm{h}}}
$$

where:

Cond $_{\mathrm{hp}}=$ conductivity of the coated grains suspension;

Cond $_{\mathrm{h}}=$ conductivity of the uncoated grains suspension . 


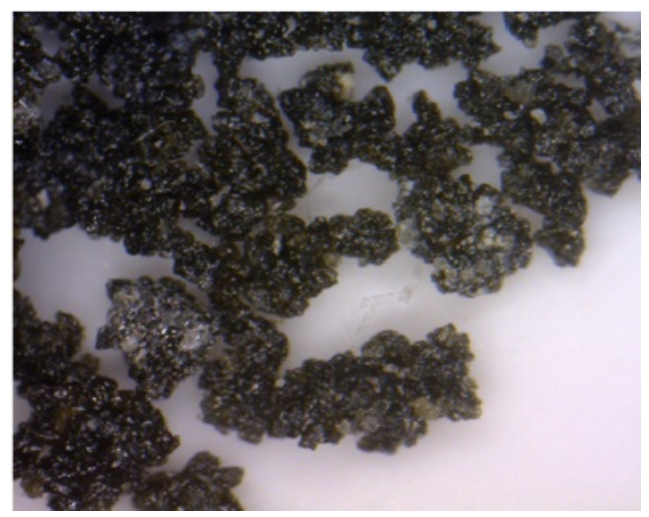

Figure 2. The grains wrapped in polymeric film

\section{Conductivity results on reactive grains}

Conductivity test on reactive grains suspension (1\%) reveals an important variation in the first minute, and a much lower rate after (Figure 3 ). It was concluded that a conductivity measurement of suspension after 1 minute can offer a good information about the covering degree, as such the kinetic of the reaction depends of the contact area on phases.

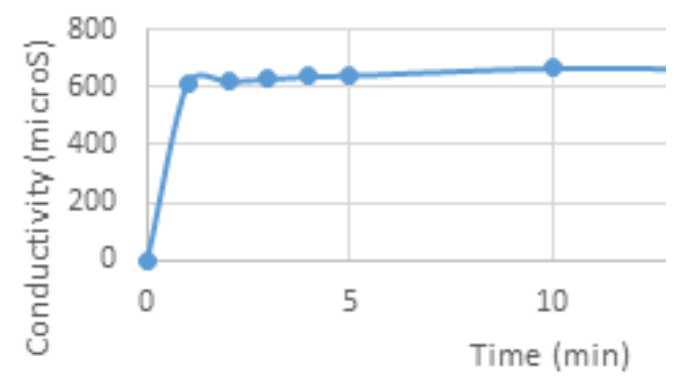

Figure 3. Level of conductivity during $10 \mathrm{~min}$. for a suspension of uncoated reactive material $(1 \%)$ in water

The conductivity results is proven to be a reliable efficiency of the smart grains addition covering, developed by the means of both methods. A number of 6 tested compositions, out of 10, reveal (Table 1) an efficiency of coverage exceeding $80 \%$, three of them approaching even $90 \%$. Considering the 10 experiments performed, no significative effect of the reactive material/polymer ratio seems to be observed. 
MIRON ZAPCIU, CONSTANTIN VOINIȚCHI, NICOLETA IONESCU, MARIUS OLTEANU

Table 1. Coating degree results for different ratio clinker/polymer

\begin{tabular}{|c|c|c|c|}
\hline \multirow{2}{*}{ Method } & No. of experiment & $\begin{array}{c}\text { Ratio: Clinker/ } \\
\text { Polymer (\%) }\end{array}$ & $\begin{array}{c}\text { Degree of } \\
\text { coating (\%) }\end{array}$ \\
\hline \multirow{4}{*}{\begin{tabular}{c} 
Method 1 \\
\cline { 2 - 4 } (PS-Polymer Solution)
\end{tabular}} & 1 & 54 & 83 \\
\cline { 2 - 4 } & 2 & 27 & 85 \\
\cline { 2 - 4 } & 3 & 18 & 88 \\
\cline { 2 - 4 } & 4 & 9 & 89 \\
\cline { 2 - 4 } & 5 & 5 & 79 \\
\cline { 2 - 4 } & 7 & 10 & 66 \\
\hline Method 2 & 8 & 20 & 71 \\
\hline (MP- Melted Polymer) & 10 & 11.3 & 87 \\
\hline
\end{tabular}

The conductivity development over time, for the reactive grains, without coating (blue line) and the coated grains (Methods 1 and 2 ) is presented in the Figure 4.
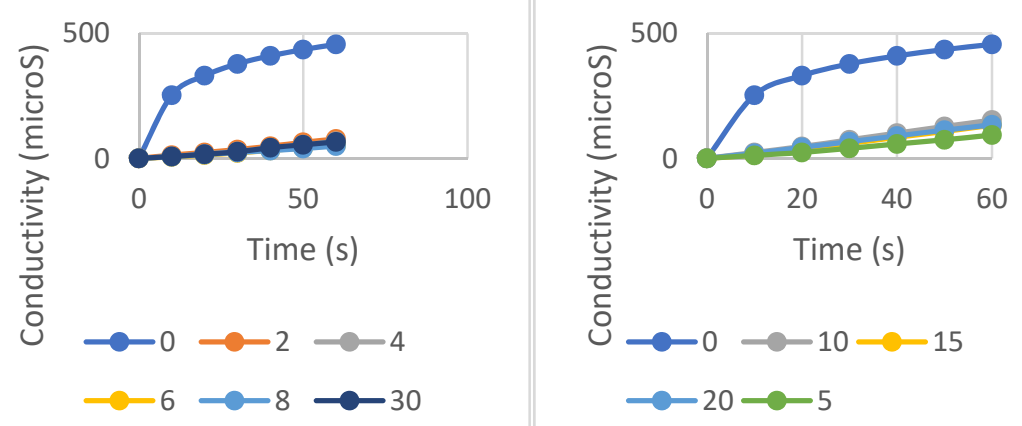

a)

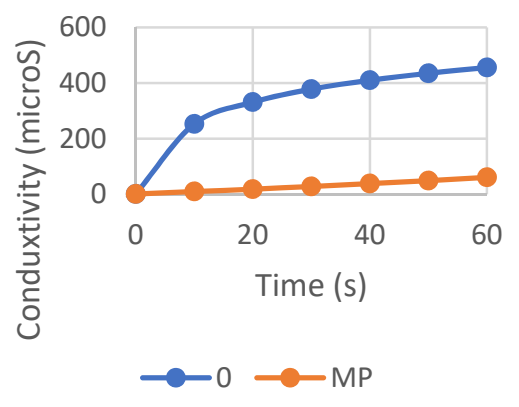

b)

Figure 4. Variation of the conductivity during $1 \mathrm{~min}$. for uncoated $(0)$ and coated grains: a) using Method 1 (Polymer Solution) and b) Method 2 (Melted Polymer) 


\section{3) Results and discussion on self-repairing effect}

In order to check the self-repairing effect of a smart addition grains, it has been carried out a related test.

The smart grains addition with a reactive material/polymer ratio of $9 \%$ was introduced into a standardised mortar performed, according to EN 196-1 standard, in different proportions. An CEM I52.5R cement was used to hydrate granules as much as possible and to reduce the natural self-repairing effect.

A degree of self-repairing (Healing Degree - HD) of the crack was defined as follows:

where:

$$
H D(\%)=100^{*}\left[\left(I_{f P}-I_{n P}\right)-\left(I_{f R}-I_{n R}\right)\right] /\left(I_{f P}-I_{n P}\right)
$$

$\mathrm{I}_{\mathrm{fP}}=$ intensity of the current through the crack;

$\mathrm{I}_{\mathrm{nP}}=$ intensity of the current through the uncracked aria;

$\mathrm{I}_{\mathrm{fR}}=$ intensity of the current through the crack on the reference sample;

$I_{n R}=$ intensity of the current through the uncracked aria on the reference sample.

The intensity of current through the crack $I_{c}$ is the difference between intensity of the current on the cracked aria $I_{f p}$ and uncracked $I_{n p}$ area.

Results for three samples are presented in the Figure 5 and reveals a good self-repairing properties of the smart addition grains.

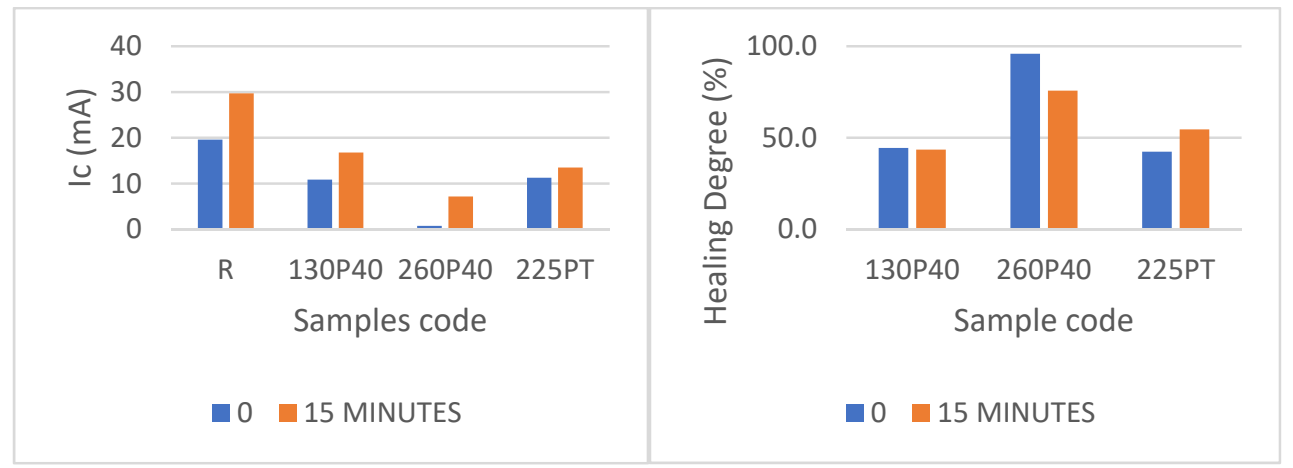

Figure 5. Intensity of current through crack after 0 and 15 minutes (left) and degree of healing $(\mathrm{HD})$ of the crack (right)

For all 3 samples used, in which the smart grain dosage represents 130,260 and $225 \mathrm{~kg} / \mathrm{m} 3$, respectively. HD is around $50 \%$ and they have a maximum of $70 \%$ compared to the standard reference sample. The sample no.2, with an addition of $260 \mathrm{~kg}$ 'm3, was the best composition on self-repair. 


\section{CONCLUSIONS}

The material with a matrix based on cement, mortar or concrete, with self-repair properties (Fig. 1), is characterized by the fact that it contains the addition of reactive granules, encapsulated in our experiment with a polymeric film $(\mathrm{C} 8 \mathrm{H} 8)$ n.

The authors' recommendation is that the reactive granules have diameters in the range of 90-160 micrometers, their mass representing at least $80 \%$ of the total mass of the addition with self-repair properties. The total mass of the addition represents $5-10 \%$ of the total mass of the material with cement-based matrix and the following materials can be used: clinker, aluminous cement, blast furnace slag as ground cementitious material, hydraulically active materials (power plant ash, trass) or quicklime.

The material with a matrix based on cement, mortar or concrete, with self-repairing properties, is characterized in that the encapsulation with the polymer film is obtained by immersing the reactive granules in polystyrene solution, a solution that represents a maximum of $20 \%$ of the total mass of the addition with self-repair properties. The melting temperature of polystyrene was $240^{\circ} \mathrm{C}$.

The self-repairing effect of intelligent addition grains has been proven on the mortars by electro diffusion of chloride ions. Crack healing degrees of more than $70 \%$ were obtained for some compositions.

The influence of the smart grains addition to mechanical resistance (resistance to static compression and bending test) of the material has been assessed using EN 196-1 standard and a small increase in all mechanicall performances was observed [18]; this demonstrates the lack of negative effects of the added grains on the mechanical strength of the material.

In order to implement the results of the research [20-21], it was necessary to establish the manufacture of a small size of a bridge beam using smart grains material. In the forthcoming work, in real operating and related exploitation situations, the behavior of this sample versus classical material will be compared.

\section{EXPERIMENTAL SECTION}

\section{Procedure and requirements for obtaining test specimens}

In order to demonstrate experimentally the self-repairing effect of new material an active hydraulic material was used, covered with a layer of waterproofing polymer and was tested its positive effect. The necessary test samples must be obtained after completing the following steps: 
coating;

-obtaining granules of active hydraulic material with waterproofing

-accelerated ageing of concrete;

-controlled cracking of the sample;

-use of an appropriate method for highlighting the self-healing effect;

- separation of the influence of the natural self-healing effect of concrete from that due to self-repairing addition.

The active hydraulic material must compulsory meet certain requirements:

- the reactive material generates new compounds by reaction with water or ions dissolved therein, compounds that will be stored in the crack and thus restricting the access of aggressive agents.

- the reactive material should not contain or generate sulphates, chlorides, alkalis or other aggressive concrete ions. The presence of sulphates can lead to the formation of ettringite with a remedial action by creating a barrier to water entering, but at the same time there is also the risk of an out-of-control reaction that can lead to the destruction of concrete.

- the reactive material must not negatively influence the hydration and hardening properties of Portland cement in case of accidental break-in of waterproof protection.

The following requirements must be met for the waterproof coating polymer:

- protect the reactive material from the water until the crack will crosses it;

- be adherent to reactive granules (adhesion to reactive material granules helps to withstand mechanical shocks during mixing);

- not negatively influence cement hydration processes;

- withstand efforts during the concrete preparation process;

- be resistant in the alkaline concrete environment;

- do not suffer positive volume variations in alkaline environment;

- be brittle so as to break and allow contact with the water to infiltrate;

- be available in large quantities;

- ability to be used in the technological processes - soluble in ordinary solvents or a reasonably low melting point; pollution.

- possibly to be a recyclable material to reduce costs and environment

For each sample were added $2.25 \mathrm{~g}$ polypropylene fibres so that the crack caused in the material does not lead to the complete rupture of the samples. Samples with dosages of $0 \mathrm{~kg} / \mathrm{m}^{3}$ smart addition grains were casted as the reference mortar $R$, with $130 \mathrm{~kg} / \mathrm{m}^{3}$ smart addition as sample $130 \mathrm{P} 40$, $260 \mathrm{~kg} / \mathrm{m}^{3}$ as sample $260 \mathrm{P} 40$ and $225 \mathrm{~kg} / \mathrm{m}^{3}$ smart addition obtained by melting method as sample 225PT. 
Fraction less than $0,5 \mathrm{~mm}$ from the standardized sand was partially removed in a volume equal to that of the smart addition grains used. The samples were casted into a classic $160 \times 40 \times 40 \mathrm{~mm}$ mould, modified by removing an intermediate wall. The mortar was compacted and stored 1 day according to EN 196-1 standard. Accelerated aging is obtained by a hygrothermal treatment at $80^{\circ} \mathrm{C}$ in a water bath.

\section{Experiment to control the crack of samples}

The following procedure is used for controlled cracking of the sample: after 2 weeks of curing, mortar samples are removed from water bath and a $5 \mathrm{~mm}$ thick and $15 \mathrm{~mm}$ deep channel was cut with diamond disc saw in the median area, across the sample, to direct the crack. The sample was instrumented with a crack monitoring device mounted with axis at $15 \mathrm{~mm}$ from the bottom of the sample and comprising the median area where the cracking will occur. The sample is placed on two supports at a $100 \mathrm{~mm}$ apart and a force is applied via a roller in the median area (Figure 6).

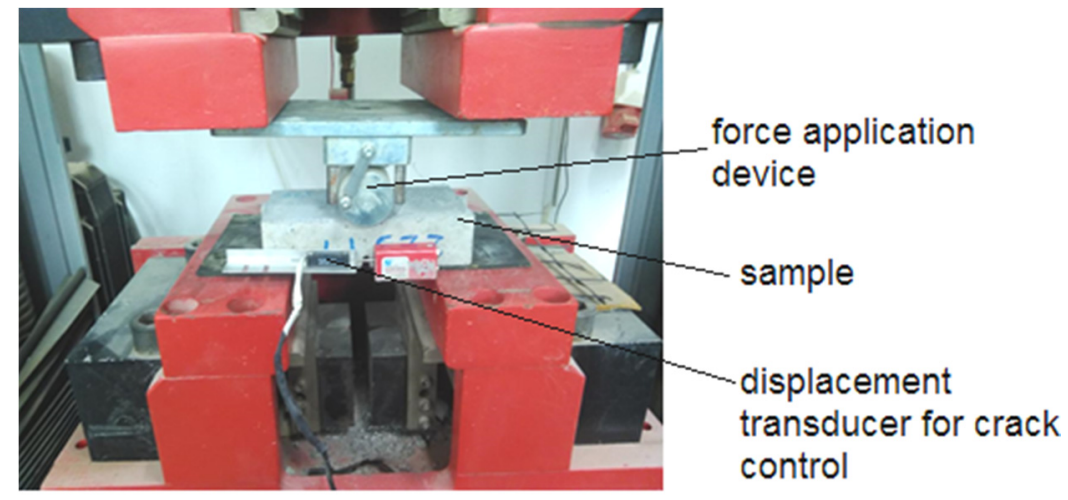

Figure 6. Experimental arrangement in order to obtaining a fixed crack width

The increase in force stops at the time of the crack appearing and then it adjusts its intensity until the desired opening is obtained. The test machine was turned off in this position and 2 metal fibers of appropriate size were applied to the side of the sample using appropriate adhesive. After hardening, the crack monitoring device was removed and two other fibers were applied in its place.

The samples are introduced into a water bath, but not in direct contact with water, to speed up the self-healing process. After an appropriate period, samples were extracted from the water bath and a channel with the same 
specifications like the first one, centered at $27 \mathrm{~mm}$ from the end of the prisms was cutted.

The method of highlighting the self-repairing effect is based on the amount of electricity passed through the sample [20]. In order to highlight the influence of the crack on the transport of electric charges and implicitly the diffusion of chloride ions, the tests were carried out in areas with channels cut into samples, with or without crack.

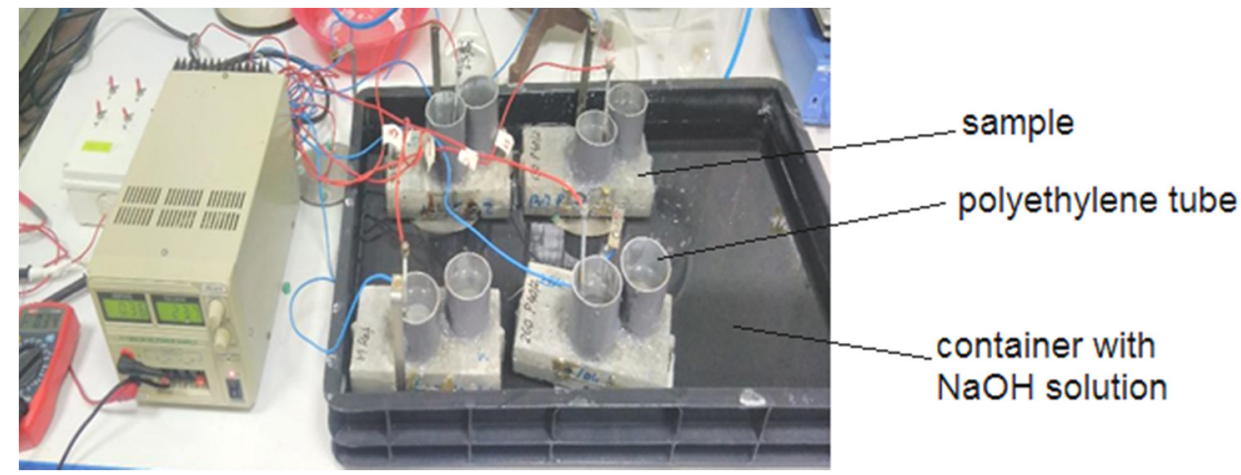

Figure 7. Experimental arrangement of the samples highlighting the self-repairing effect based on the amount of electricity passed through the sample

Two polyethylene tubes $50 \mathrm{~mm}$ in diameter were sticked on the casting face using a silicone seal, one in the central area above the crack and one above the channel centered at $27 \mathrm{~mm}$ from the prism end. All the four samples (Figure 7) were dried in an oven and saturated with water in vacuum at $20 \mathrm{~mm} \mathrm{Hg}$. A $3 \% \mathrm{NaCl}$ solution is inserted into the polyethylene tubes. The samples thus prepared were introduced in a $0.1 \%$ solution of $\mathrm{NaOH}$ were placed in a $0.1 \% \mathrm{NaOH}$ solution in an insulating plastic container.

A $24 \mathrm{~V} \mathrm{DC}$ voltage was applied for 15 minutes and the intensity of the electrical current through the cracked $I_{\mathrm{fP}}$ and uncracked $\mathrm{I}_{\mathrm{nP}}$ area of each sample was measured, including the $I_{f R}$ and $I_{n R}$ in reference sample $R$. The intensity of current through the crack $I_{c}$ is the difference between intensity of the current flowing through the cracked $\left(\mathrm{I}_{\mathrm{fP}}\right)$ and uncracked $\left(\mathrm{I}_{\mathrm{nP}}\right)$ area.

\section{Experimental validation of self-repairing effect using SEM}

The action of intelligent addition grains has been validated by electronic microscopy (SEM) on sections obtained from the cracked and selfrepaired area (Figure 8). 


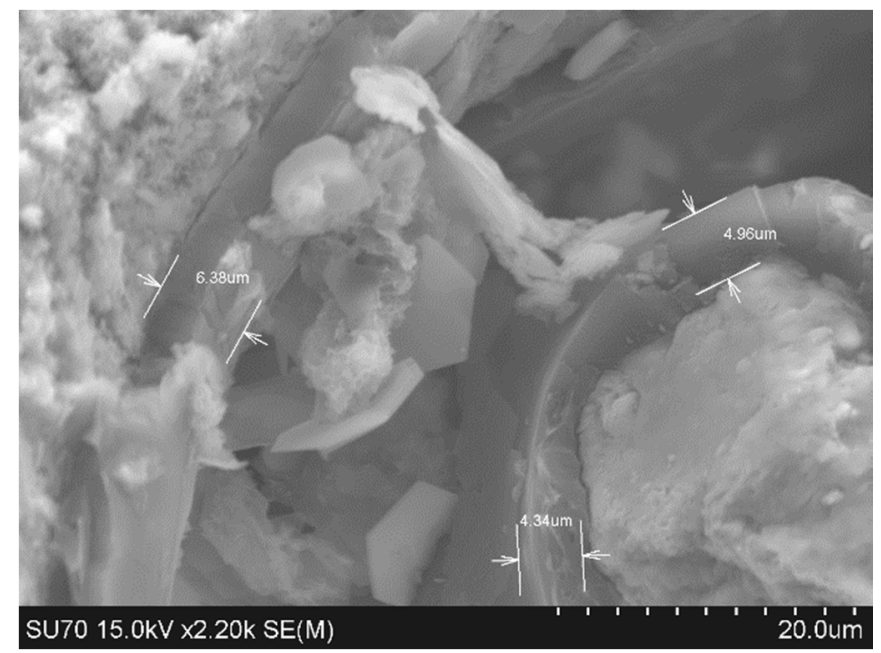

Figure 8. SEM capture; evaluation of the healing degree

A polymer coating of few micrometers thick $(4.3 \mu \mathrm{m})$ and some products resulted from hydration could be viewed using SEM. Considering the largest uniaxial size of a polymer film-coated reactive addition granule equal to $193 \mu \mathrm{m}$, respectively the uniaxial size of the crystallization zone of the hydrocomposites formed after the destruction of the polymer film (cured area $\approx 123 \mu \mathrm{m}$ ), a $64 \% \mathrm{HD}$ resulted for this sample.

It is emphasized that no microstructural elements were identified to highlight discontinuities or compositional heterogeneities of the samples and there is no suspicion about addition grains incompatibility in the cement matrix.

\section{ACKNOWLEDGMENTS}

This paper is supported by the Programme: "Innovative solutions for transport infrastructure protection by the use of building materials with special self-maintenance and self-repair properties", Programme code: 6 PS I 13.09.2019, financed by the Ministry of Education and Research.

\section{REFERENCES}

1. * * * WIPO Patent number WO 2017/116354, 2017, pp. 8-10.

2. V. Li; E.H. Yang; Patent number 20080261027, USA, 2008, pp. 5-9.

3. Ed. G. Nawy; Concrete construction engineering handbook. 2nd Edition, Boca Raton: Taylor \& Francis Group, 2008, pp. 15-19.

4. D. Snoeck; N. De Belie; J. Mat. Civil Eng. 04015086, 2015, pp.1-11. 
5. D. Snoeck; N. De Belie; J. Mat. Civil Eng., 2015, 28(1), 50-86.

6. D. Snoeck; J. Dewanckel; V. Cnudde; N. De Belie; Cement and Concrete Composites, 2016, 65, 83-93.

7. M. Şahmaran; G. Yildirim; T.K. Erdem; Cement and Concrete Composites, 35(1), 2013, pp.89-101.

8. P. Termkhajornkit; T. Nawa; Y. Yamashiro; T. Saito; Cement and Concrete Composites, 31(3), 2009, pp.195-203.

9. K. Van Tittelboom; N. De Belie; Materials, 6(6), 2013, pp. 2182-2217.

10. K. Van Tittelboom; E. Gruyaert; H. Rahier; N.De Belie; Construction and Building Materials, 37, 2012, pp.349-359.

11. A. Witze; Nature News, 2017, pp. 15-25.

12. ** ${ }^{*}$ OSIM Patent application no.A/00022, 2020, Bulletin of OSIM, RO-BOPI no.7/2020, pp. 31.

13. E.H. Yang; V.C. Li; Cement and Concrete Research, 42(8), 2012, pp.1066-1071.

14. E.H. Yang; Y. Yang; V.C. Li; ACI Materials Journal, 104(6), 2007, pp. 303-311.

15. G. Yildirim; M. Sahmaran; H.U. Ahmed; Journal of Materials in Civil Engineering, 27(6), 2014, pp. 87-89.

16. G. Yildirim; M. Şahmaran; H.Ahmed; Journal of Materials in Civil Engineering, 27(6), 2014.

17. Z. Zhang; S. Qian; H. Ma; Construction and Building Materials, 52, 2014, pp.17-23.

18. C. Voinițchi; C. Baeră; M. Zapciu; C. Matei; H. Szilágyi; N. Ionescu; F. Tudorie; Annals of the Academy of Romanian Scientists, Series on Engineering Sciences, ISSN 2066-8570, Vol.12, No.1, 2020, pp. 89-102.

19. A. Cuibus; M. Gorea; N. Har; Z. Kiss; Studia UBB Chemia, LIX, 4, 2014, pp. 75-86. 20. * * * ASTM C1202-19 Standard Test Method, 2019.

21. ${ }^{*} * *$ Sectoral project 6PS/13.09.2019, financed by Ministry of Education and Research: Phase III, 2020, Chapter: Elaboration of the technology implementation manual, pp. 11-15. 
